\title{
Presynaptic Cav2.1 and Cav2.2 Differentially Influence Release Dynamics at Hippocampal Excitatory Synapses
}

\author{
Anita Scheuber, Richard Miles, and Jean Christophe Poncer \\ Institut National de la Santé et de la Recherche Médicale, Equipe Mixte 224 Cortex et Epilepsie, Centre Hospitalier Universitaire Pitié-Salpêtrière, 75013 \\ Paris, France
}

Presynaptic calcium influx at most excitatory central synapses is carried by both Cav2.1 and Cav2.2 channels. The kinetics and modulation of Cav2.1 and Cav2.2 channels differ and may affect presynaptic calcium influx. We compared release dynamics at CA3/CA1 synapses in rat hippocampus after selective blockade of either channel subtype and subsequent quantal content restoration. Selective blockade of Cav2.1 channels enhanced paired-pulse facilitation, whereas blockade of Cav2.2 channels decreased it. This effect was observed at short $(50 \mathrm{msec})$ but not longer $(500 \mathrm{msec})$ intervals and was maintained during prolonged bursts of presynaptic activity. It did not reflect differences in the distance of the channels from the calcium sensor. The suppression of this effect by preincubation with the $\mathrm{G}_{\mathrm{o} / \mathrm{i}}$-protein inhibitor pertussis toxin suggests instead that high-frequency stimulation relieves inhibition of Cav2.2 by $\mathrm{G}_{\mathrm{o} / \mathrm{i}}$, thereby increasing the number of available channels.

Key words: synaptic; plasticity; hippocampus; channels; calcium; G-protein

\section{Introduction}

Transmitter release at central synapses is triggered by calcium influx through voltage-dependent channels. Presynaptic calcium influx mediating release is carried predominantly by both Cav 2.2 and Cav2.1 channels (Luebke et al., 1993; Takahashi and Momiyama, 1993; Regehr and Mintz, 1994; Wheeler et al., 1994), although Cav2.3 and Cav1.2 may be recruited under specific circumstances (Jensen and Mody, 2001; Dietrich et al., 2003). In contrast, some GABAergic synapses use mostly one channel subtype or the other (Poncer et al., 1997; Brager et al., 2003). However, other synapses initially express both subtypes and rely on Cav2.1 only after maturation (Forsythe et al., 1998; Rosato-Siri and Uchitel, 1999).

What is the physiological relevance of these different presynaptic calcium channels? Several of their properties seem likely to influence transmitter release.

First, Cav2.1 and Cav2.2 are described as slowly and rapidly inactivating, respectively (Catterall, 1995). The intrinsic inactivation of the pore-forming $\alpha 1$ subunits is further influenced through interactions with ancillary subunits (Stotz and Zamponi, 2001) and calcium-dependent mechanisms (Budde et al., 2002; Liang et al., 2003). The latter may contribute to the rapid decline of presynaptic Cav2.1 currents during repetitive activation (Forsythe et al., 1998).

\footnotetext{
Received May 3, 2004; revised 0ct. 6, 2004; accepted 0ct. 7, 2004.

This work was supported by a Fellowship from the Swiss National Science Foundation (A.S.) and the Centre National de la Recherche Scientifique (J.C.P.). We thank Marie-Chantal Marty for technical assistance and Philippe Ascher and Scott M. Thompson for helpful discussions and comments on this manuscript.

Correspondence should be addressed to Jean Christophe Poncer, Institut National de la Santé et de la Recherche Médicale, Equipe Mixte 224 Cortex et Epilepsie, 105 boulevard de I'Hôpital, 75013 Paris, France. E-mail: jcponcer@chups.jussieu.fr.

DOI:10.1523/JNEUROSCI.1664-04.2004

Copyright $(\odot 2004$ Society for Neuroscience $\quad 0270-6474 / 04 / 2410402-08 \$ 15.00 / 0$
}

Second, many neurotransmitters inhibit Cav2.1 and Cav2.2 via activation of G-protein-coupled receptors (Hille, 1994). This inhibition involves direct interaction between $\mathrm{G}_{\beta \gamma}$ subunits and the $\alpha 1$ subunit of the channel (Zamponi and Snutch, 1998b), shifting the channel opening regimen toward low open probabilities (Bean, 1989; Dolphin, 1998). Such inhibition was shown to be stronger for Cav2.2 than Cav2.1 (Currie and Fox, 1997; Agler et al., 2003) and to alter Cav2.2 but not Cav2.1 current kinetics (Colecraft et al., 2000). In addition, relief of Cav2.2 inhibition is more sensitive to subtle changes in the amplitude and shape of a depolarizing pulse (Currie and Fox, 2002).

Third, at some synapses expressing both channel subtypes, Cav2.1 were found more effectively coupled to transmitter release than Cav2.2 (Mintz et al., 1995; Reid et al., 1998; Wu et al., 1999) (but see Wu and Saggau, 1994b). Colabeling experiments at the calyx of Held suggests Cav2.2 are situated at greater distances from the putative calcium sensor (Wu et al., 1999). Such a remote location would both decrease the efficacy of $\mathrm{Ca}^{2+}$ influx to trigger release and augment the impact of endogenous $\mathrm{Ca}^{2+}$ buffers on release dynamics during repetitive stimulation (Blatow et al., 2003).

Although these different properties and distribution of presynaptic calcium channels should affect synaptic strength, little direct evidence exists for a differential effect on transmission dynamics (Reid et al., 2003). Here, we examined the properties of synaptic transmission mediated by Cav2.1 and Cav2.2 at Schaffer collateral (SC) inputs onto CA1 pyramidal cells, in which both channel subtypes are expressed. We compared transmission dynamics when both subtypes contribute to the presynaptic calcium influx and after selective blockade of either subtype. We show that activity-dependent facilitation at these synapses is greater when Cav2.2 rather than Cav2.1 mediate transmission and suggest that this difference reflects a stronger use-dependent 
relief from G-protein-mediated inhibition of presynaptic Cav2.2 channels.

\section{Materials and Methods}

Transverse hippocampal slices were prepared from postnatal day 11-15 Sprague Dawley rats. Rats were anesthetized by intraperitoneal injection of ketamine and xylazine ( 80 and $20 \mathrm{mg} / \mathrm{kg}$, respectively) and decapitated. The brain was quickly removed and immersed in low-sodium, ice-cold artificial CSF (low $\mathrm{Na}^{+}$-ACSF) equilibrated with $95 \% \mathrm{O}_{2}-5 \%$ $\mathrm{CO}_{2}$. The composition of the low $\mathrm{Na}^{+}$-ACSF was as follows: $248 \mathrm{~mm}$ sucrose, $26 \mathrm{~mm} \mathrm{NaHCO}_{3}, 10 \mathrm{~mm}$ glucose, $5 \mathrm{~mm} \mathrm{MgCl}_{2}, 4 \mathrm{~mm} \mathrm{KCl}, 1 \mathrm{~mm}$ $\mathrm{CaCl}_{2}$, and $0.005 \%$ Phenol Red. Slices, $350 \mu \mathrm{m}$ thick, were prepared using a vibroslicer (DTK 1000; Dosaka, Kyoto, Japan) and incubated at room temperature in ACSF bubbled with $95 \% \mathrm{O}_{2}-5 \% \mathrm{CO}_{2}$. ACSF was composed of the following (in mM): $124 \mathrm{NaCl}, 26.2 \mathrm{NaHCO}_{3}, 11$ D-glucose, $2.5 \mathrm{KCl}, 1 \mathrm{NaH}_{2} \mathrm{PO}_{4}, 3 \mathrm{CaCl}_{2}$ and $2 \mathrm{MgCl}_{2}$. For recording, slices were transferred to a submerged chamber mounted on a Zeiss (Le Pecq, France) Axioskop microscope and superfused with ACSF at a rate of $2-2.5 \mathrm{ml} / \mathrm{min}$. To isolate EPSCs, bicuculline methochloride $(20 \mu \mathrm{M})$ was added to the ACSF after a cut was made between the CA3 and CA1 areas to prevent epileptiform activity.

Whole-cell recordings from CA1 pyramidal neurons were made under visual guidance using patch electrodes (3-5 $\mathrm{M} \Omega$ resistance) made from borosilicate glass capillaries (Hilgenberg, Malsfeld, Germany) and filled with the following (in mM): $115 \mathrm{CsMeSO}_{3}, 20 \mathrm{CsCl}, 10 \mathrm{HEPES}, 10 \mathrm{EGTA}$, 1 BAPTA, $1.8 \mathrm{MgCl}_{2}, 4 \mathrm{Mg}$-ATP, $0.4 \mathrm{Na}_{3}$-GTP, and $10 \mathrm{~mm} \mathrm{Na}$ phosphocreatine. In experiments to examine the presynaptic actions of baclofen, QX-314 [2(triethylamino)-N-(2,6-dimethylphenyl) acetamine] (1 $\mathrm{mM}$ ) was added to the internal solution to suppress postsynaptic $\mathrm{GABA}_{\mathrm{B}}$ currents. EPSCs were evoked at $0.1 \mathrm{~Hz}$ using extracellular stimulation of Schaffer collaterals with a glass pipette filled with ACSF while holding the cell at $-60 \mathrm{mV}$. Signals were acquired and filtered at 5 $\mathrm{kHz}$ using an Axopatch $1 \mathrm{D}$ amplifier and digitized at $20 \mathrm{kHz}$ using Clampex software of the pClamp 8 suite (Axon Instruments, Union City, CA). EPSC amplitudes and access resistance were monitored online. EPSC amplitudes were measured offline as the difference between a 2 msec window placed just before the stimulus artifact and a 2-3 msec window placed at the peak of the response. For display, stimulation artifacts were digitally subtracted. Paired-pulse ratios (PPRs) were computed from sliding averages of $30-50$ consecutive episodes, as $\mathrm{EPSC}_{2} /$ $\mathrm{EPSC}_{1}$, in which EPSC $\mathrm{E}_{1}$ and $\mathrm{EPSC}_{2}$ represent the amplitude of the first and the second EPSC, respectively. When the quantal content of the first EPSC was to be restored after toxin application, external $\left[\mathrm{Ca}^{2+}\right] /\left[\mathrm{Mg}^{2+}\right]$ ratio was typically raised from 0.7 to 4 (range, 1.5-9), while keeping divalent cation concentration constant. Consecutive episodes were then selected so that the mean EPSC $_{1}$ matched control EPSC $1 \pm 0.3 \%$, which

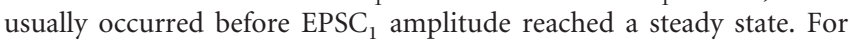
monitoring afferent volleys, field recordings were made using a patch pipette filled with ACSF placed in stratum radiatum in the CA1 area, $\sim 100 \mu \mathrm{m}$ apart from the stimulating electrode, in the presence of D,L-AP-5 (100 $\mu \mathrm{M})$, 2,3-dioxo-6-nitro-1,2,3,4-tetrahydroxybenzo $[f]$ quinoxaline-7-sulfonamide disodium salt (NBQX) $(20 \mu \mathrm{M})$, and bicuculline $(20 \mu \mathrm{M})$. Signals were acquired at $20 \mathrm{kHz}$ and filtered at $5 \mathrm{kHz}$ using an Axopatch 1D amplifier. Volley amplitudes were measured between a $0.5 \mathrm{msec}$ baseline preceding the stimulation artifact and the peak of the negative component of the field potential, after subtraction of the artifact recorded in the presence of tetrodotoxin $(1 \mu \mathrm{M})$. Average values are expressed as mean \pm SEM. Statistical significance was assessed using nonparametric paired (Wilcoxon) or unpaired (Mann-Whitney) tests. Correlation between variables was assessed with the nonparametric Spearman rank order correlation test, using SigmaStat 3.0 (SPSS, Parisla-Défense, France).

For experiments requiring pretreatment with pertussis toxin (PTx), slices were maintained in culture as described previously (Musleh et al., 1997) and grown at $35^{\circ} \mathrm{C}$ on polytetrafluoroethylene culture inserts for $5-8 \mathrm{~d}$ in a humidified $\mathrm{CO}_{2}$ incubator. Culture medium was replaced 3 times per week. PTx at $500 \mathrm{~nm}$ was added to the culture medium 48 and again $24 \mathrm{hr}$ before experiments.

Drugs were obtained from the following sources: bicuculline metho-
A

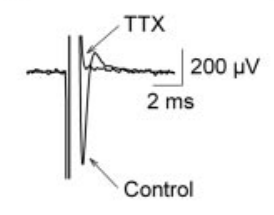

B

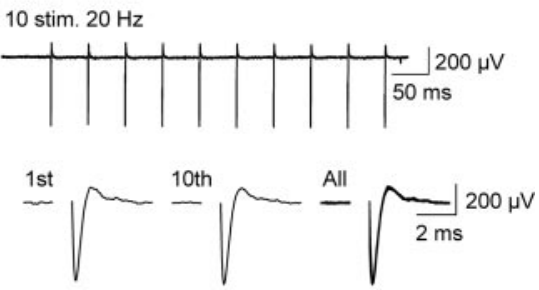

C

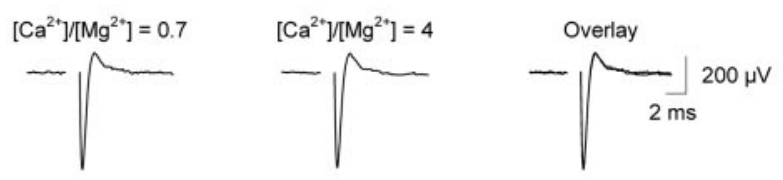

D
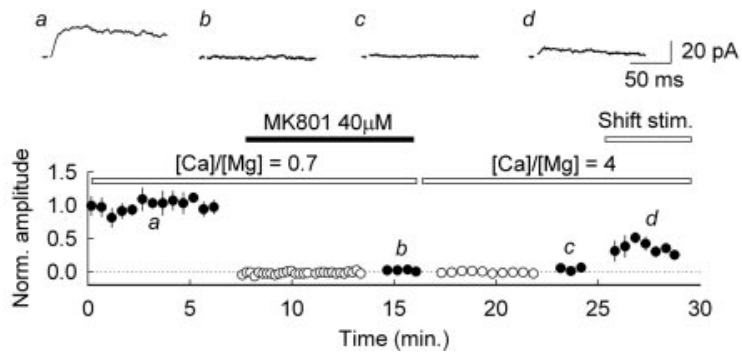

Figure 1. Changing $\left[\mathrm{Ca}^{2+}\right] /\left[\mathrm{Mg}^{2+}\right]$ while maintaining cation concentration constant does not lead to recruitment of more or fewer synapses. $A-C$, Afferent volley evoked by Schaffer collateral stimulation was recorded in the stratum radiatum in the CA1 area. Neither the shape nor the amplitude of afferent volley was significantly changed during 10 stimuli delivered at 20 $\mathrm{Hz}$. They were also unchanged when external $\left[\mathrm{Ca}^{2+}\right] /\left[\mathrm{Mg}^{2+}\right]$ was raised from 2:3 to 4:1. D, NMDAR EPSCs evoked by SC stimulation at $0.1 \mathrm{~Hz}$ in a CA1 pyramidal cell held at $V_{\mathrm{H}}=+40 \mathrm{mV}$ (filled circles). After a baseline ( $a$ ) was established, $V_{H}$ was set to $-60 \mathrm{mV}$ (open circles) and afferent stimulation resumed at $0.25 \mathrm{~Hz}$ while applying MK-801 $(40 \mu \mathrm{M})$. The cell was returned to $+40 \mathrm{mV}(b)$ to check for complete block of the NMDAR EPSC, showing that all stimulated synapses had been blocked by MK-801. After washout of MK-801, $\left[\mathrm{Ca}^{2+}\right] /\left[\mathrm{Mg}^{2+}\right]$ was raised form 2:3 to 4:1, $V_{H}$ was set to $-60 \mathrm{mV}$, and stimulation was resumed for $\sim 5-6 \mathrm{~min}$. NMDAR EPSC was then assessed again at $+40 \mathrm{mV}(\mathrm{c})$. Changing $\left[\mathrm{Ca}^{2+}\right] /\left[\mathrm{Mg}^{2+}\right]$ did not induce the reemergence of an EPSC, suggesting that no additional synapse was recruited. In contrast, when the stimulation electrode was moved sideways by $\sim 25 \mu \mathrm{m}$, a significant NMDAR EPSC was restored, reflecting recruitment of synapses that had not been stimulated previously $(d)$. Top traces represent averages from $10-40$ consecutive EPSCs from an individual experiment. The scatter plot represents the average of four experiments. Each point represents the average amplitude of three consecutive EPSCs, normalized to control EPSC amplitude.

chloride (ICN, Orsay, France); D-AP-5, NBQX, and (5S, 10R)-(+)-5methyl-10,11-dihydro-5H-dibenzo [a,d] cyclohepten-5,10-imine maleate (MK-801) (Fisher Bioblock, Illkirch, France); $\omega$-conotoxin GVIA and $\omega$-agatoxin IVA (Bachem, Voisins le Bretonneux, France); and pertussis toxin (Merck Eurolab, Fontenay-sous-Bois, France).

\section{Results}

Changes in release dynamics after blockade of Cav2.2 versus

Cav2.1 calcium channels

EPSCs evoked in CA1 pyramidal neurons by extracellular stimulation of SC afferents were isolated in the presence of the $\mathrm{GABA}_{\mathrm{A}}$ receptor antagonist bicuculline $(20 \mu \mathrm{M})$. To assess how distinct presynaptic $\mathrm{Ca}^{2+}$ channels control release dynamics at the same set of synapses, we compared the response to pairs or trains of afferent stimuli in control conditions and after blockade of either channel subtype using the irreversible blockers $\omega$-conotoxin GVIA and $\omega$-agatoxin IVA. Such comparison is only valid when two conditions are fulfilled. The first is that PPRs should remain stable over time. To prevent any bias in PPR estimation attribut- 
able to quantal amplitude fluctuations (Kim and Alger, 2001), PPRs were calculated from the sliding average of 30-50 consecutive EPSCs. In these conditions, we found that the averaged PPR varied at most by $5.2 \pm 0.7 \%$ of its mean over the course of a $>25$ min recording (coefficient of variation, $2.5 \pm 0.3 \% ; n=7$ ).

The second condition is that the quantal content of the first EPSC should be kept constant, because PPR varies with release probability (Debanne et al., 1996; Dobrunz and Stevens, 1997). Because blocking Cav2.2 or Cav2.1 channels reduces EPSC amplitude at these synapses by $>50 \%$ (Takahashi and Momiyama, 1993), we restored synaptic transmission to control levels by adjusting the external $\left[\mathrm{Ca}^{2+}\right] /\left[\mathrm{Mg}^{2+}\right]$ ratio at a constant divalent cation concentration ( $5 \mathrm{~mm}$; see Material and Methods). This change might alter the excitability of presynaptic fibers (Hille, 1968), thereby changing the number of synapses recruited by afferent stimulation. We tested this possibility in two sets of experiments. We first examined the effects of a change in external $\left[\mathrm{Ca}^{2+}\right] /\left[\mathrm{Mg}^{2+}\right]$ ratio on the shape and amplitude of the afferent volley evoked by stimulation of Schaffer collaterals in the presence of bicuculline $(20 \mu \mathrm{M}), \mathrm{D}, \mathrm{L}-\mathrm{AP}-5(100 \mu \mathrm{M})$, and NBQX $(20$ $\mu \mathrm{M})$. A patch pipette placed $\sim 100 \mu \mathrm{m}$ apart from the stimulating electrode could usually detect a biphasic volley of a few hundred microvolts (Fig. 1A) (see Material and Methods). This signal remained unaffected when trains of 10 stimuli were delivered at $20 \mathrm{~Hz}$. When the external $\left[\mathrm{Ca}^{2+}\right] /\left[\mathrm{Mg}^{2+}\right]$ ratio was raised from 0.7 to 4 , the afferent volley remained unchanged in amplitude $(99.5 \pm 1.6 \%$ of control; $n=3 ; p=0.50)$ and shape, suggesting that the number of stimulated afferents was not significantly affected (Fig. 1C).

We further examined the possibility that more or fewer synapses may be recruited during changing $\left[\mathrm{Ca}^{2+}\right] /\left[\mathrm{Mg}^{2+}\right]$ ratio in experiments based on the use-dependent NMDA channel blocker MK-801 (Fig. 1D). In these experiments, after a baseline NMDA EPSC was recorded while holding the cell at $+40 \mathrm{mV}$, slices were superfused with $40 \mu \mathrm{M}$ MK-801 for $10 \mathrm{~min}$, which blocked completely the NMDA EPSC (to $2.5 \pm 0.5 \%$ of control; $n=9$ ). In this way, transmission at all stimulated synapses was suppressed. MK-801 was then rinsed out, and the external $\left[\mathrm{Ca}^{2+}\right] /\left[\mathrm{Mg}^{2+}\right]$ ratio was changed either from 0.7 to 4 or from 4 to 0.7 . As shown in Figure $1 D$, raising $\left[\mathrm{Ca}^{2+}\right] /\left[\mathrm{Mg}^{2+}\right]$ ratio from 0.7 to 4 did not cause a significant recovery of the NMDA EPSC after blockade by MK-801 (4.6 $\pm 2.2 \%$ of control, respectively; $p=0.6)$. A similar lack of NMDA ESPC recovery was observed during decreasing $\left[\mathrm{Ca}^{2+}\right] /\left[\mathrm{Mg}^{2+}\right]$ ratio from 4 to 0.7 (2.2 \pm $0.7 \%$ of control; $p=0.6$; data not shown). These results suggest that no additional synapse was recruited after changing $\left[\mathrm{Ca}^{2+}\right] /$ $\left[\mathrm{Mg}^{2+}\right]$ ratio in either direction. In contrast, moving the stimulating electrode laterally by $25-50 \mu \mathrm{m}$ restored an EPSC (31.0 \pm $2.7 \%$ of control; $p<0.001$ ), reflecting recruitment of synapses that were not previously stimulated. This EPSC remained stable over time independent of whether the stimulating electrode was moved either immediately (1-2 min) after washing out MK-801 or later. These experiments suggest that a more than fivefold change in $\left[\mathrm{Ca}^{2+}\right] /\left[\mathrm{Mg}^{2+}\right]$ ratio in conditions of fixed total divalent cation concentration does not significantly affect the number of stimulated synapses.

We could thus compare the PPR of EPSCs recorded in control conditions and after irreversible blockade of either Cav2.1 or Cav2.2 channels but with an EPSC quantal content restored to control levels (Fig. 2). In the presence of $2 \mathrm{mM} \mathrm{Ca}^{2+}$ and $3 \mathrm{mM}$ $\mathrm{Mg}^{2+}$, paired stimuli delivered $50 \mathrm{msec}$ apart usually caused a facilitation of SC-CA1 synapses (PPR, $1.59 \pm 0.08$; $n=37$ ), independent of the initial EPSC amplitude (Spearman correlation
A

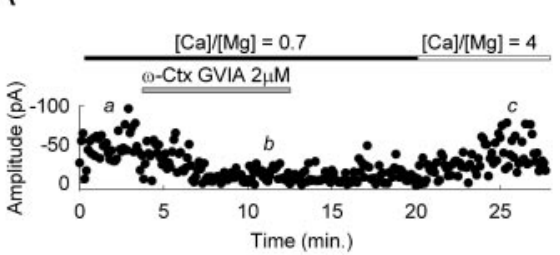

B
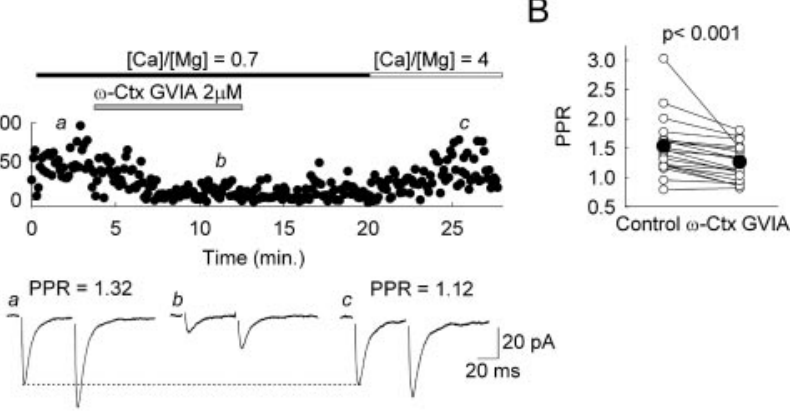

C

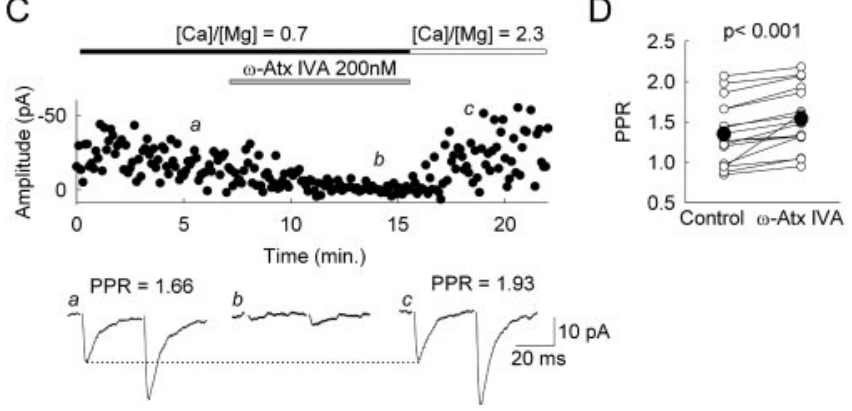

Figure 2. Synapses made to operate with either Cav2.1 or Cav2.2 show distinct dynamic profiles. EPSCs were evoked in a CA1 pyramidal cell held at $-60 \mathrm{mV}$ by pairs of SC stimuli delivered 50 msec apart. $A$, After obtaining control EPSCs, the Cav2.2 antagonist $\omega$-conotoxin GVIA (Ctx; $2 \mu \mathrm{M})$ was applied for 5-10 min, resulting in a 76\% reduction in EPSC amplitude. In this experiment, $\omega$-conotoxin GVIA was then washed out without changing $\left[\mathrm{Ca}^{2+}\right] /\left[\mathrm{Mg}^{2+}\right]$ to assess the irreversibility of the block. $\left[\mathrm{Ca}^{2+}\right] /\left[\mathrm{Mg}^{2+}\right]$ was subsequently changed from $2: 3$ to 4:1 to restore an EPSC of a similar amplitude to the control EPSC. Bottom traces represent averages of 50 consecutive EPSC recorded in control ( $a$ ), after application of $\omega$-conotoxin GVIA (b), and after quantal content recovery (c). Blocking Cav2.2 resulted in a 15\% reduction in the PPR of the response (i.e., a $63 \%$ reduction in the facilitation of the second EPSC). B, Summary plot of 20 experiments (open circles). On average, PPR decreased by $15.3 \pm 2.5 \%$ after blockade of Cav2.2 channels (filled circles). C, Similar experiment using the Cav2.1 antagonist $\omega$-agatoxin IVA (Atx; $200 \mathrm{~nm}$ ). Agatoxin caused a 92\% decrease in EPSC amplitude. The quantal content was restored by raising $\left[\mathrm{Ca}^{2+}\right] /\left[\mathrm{Mg}^{2+}\right]$ to 2.3 . In this experiment, blocking Cav2.1 channels resulted in a $16 \%$ increase in PPR, (i.e., a $41 \%$ increase in facilitation of the second EPSC). D, Summary plot of 17 experiments (open circles). 0 naverage, PPR increased by $15.8 \pm 3.9 \%$ after blockade of Cav2.1 channels (filled circles).

test; $p=0.15)$. The Cav2.2 channel antagonist $\omega$-conotoxin GVIA $(2 \mu \mathrm{M})$ reduced EPSC amplitude by $54.7 \pm 4.2 \%(n=21)$ and increased PPR by $22.4 \pm 12.3 \%$. However, when the external $\left[\mathrm{Ca}^{2+}\right] /\left[\mathrm{Mg}^{2+}\right]$ ratio was adjusted to restore the amplitude of the first EPSC (to $99.5 \pm 0.5 \%$ of control), a significant decrease in the PPR compared with control was observed $(-15.3 \pm 2.5 \%$; $n=20 ; p<0.001)$. This decreased PPR can be expressed in terms of paired-pulse facilitation (PPF). PPF was $53.9 \pm 10.5 \%$ in control conditions and $27.3 \pm 6.7 \%$ after application of $\omega$-conotoxin GVIA and quantal content recovery, thus reflecting a reduction of facilitation by $48.3 \pm 13.9 \%$.

Similarly, the Cav2.1 channel antagonist $\omega$-agatoxin IVA depressed EPSC amplitude by $74.0 \pm 5.0 \%$ and increased the PPR of the response by $40.0 \pm 10.7 \%(n=17)$. However, in contrast to $\omega$-conotoxin, after adjusting the external $\left[\mathrm{Ca}^{2+}\right] /\left[\mathrm{Mg}^{2+}\right]$ ratio to restore the amplitude of the first EPSC (to $100.0 \pm 0.3 \%$ of control), the PPR was always increased compared with control $(+15.9 \pm 3.9 \% ; n=17 ; p<0.001)$. These results show that, with an identical release probability, synapses operating with only Cav2.2 channels show more facilitation than synapses operating with only Cav2.1 channels. This effect may reflect a higher degree of facilitation associated with Cav2.2 channels or a higher degree of depression when transmission is mediated by Cav2.1 channels. 
A

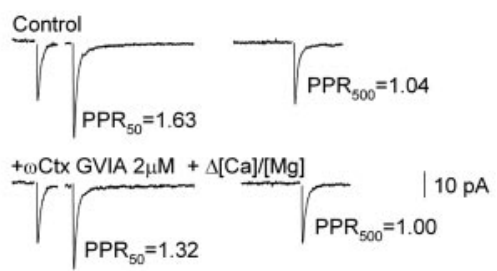

C
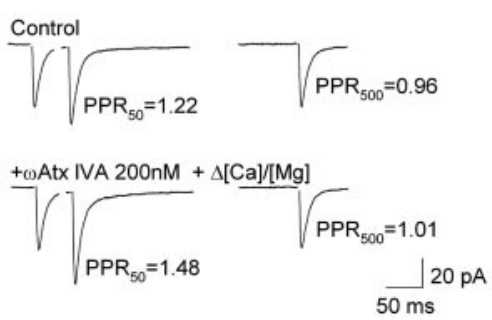

B

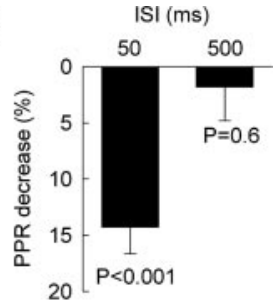

D

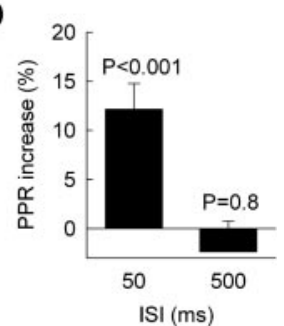

A

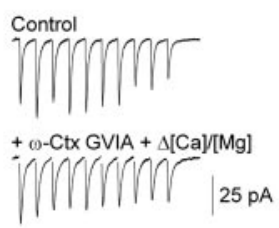

D

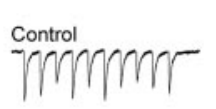

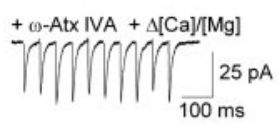

B

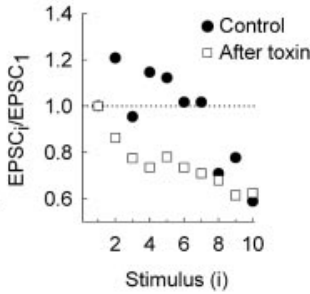

E

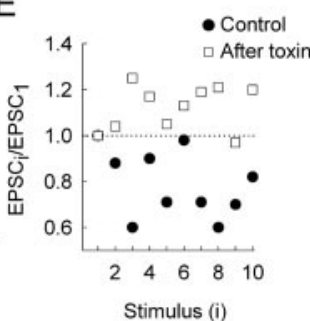

C

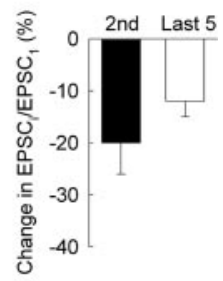

$\mathrm{F}$

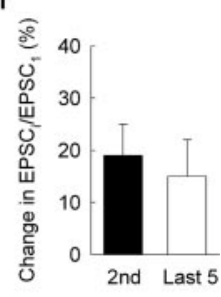

Figure 3. Temporal constraints on the effect of presynaptic Ca channel subtypes on release dynamics. $A$, EPSCs in a CA1 pyramidal cell held at $-60 \mathrm{mV}$ evoked by pairs of Schaffer collateral stimulations delivered 50 or 500 msec apart. PPF was observed at 50 but not 500 msec ISI. After application of the Cav2.2 antagonist $\omega$-conotoxin GVIA (Ctx; $2 \mu \mathrm{m})$ and subsequent quantal content recovery, the $\mathrm{PPR}_{50}$ was reduced by $19 \%$, whereas $\mathrm{PPR}_{500}$ was reduced by $<5 \%$. $B$, Summary data from eight independent experiments. C, Similar experiment using the Cav2.1 antagonist $\omega$-agatoxin IVA (Atx). After application of the toxin (200 nM) and quantal content recovery, $\mathrm{PPR}_{50}$ increased by $21 \%$, whereas $\mathrm{PPR}_{500}$ varied by only $5 \%$. D, Summary data from six independent experiments. Each trace represents the average of 50 consecutive episodes.

\section{Temporal constraints on channel}

\section{subtype-dependent plasticity}

Multiple mechanisms may contribute to an activity-dependent modulation of presynaptic calcium channels during repetitive stimulation. They operate with distinct temporal profiles and may thus affect transmission dynamics in specific frequency ranges. For instance, $\mathrm{Ca}^{2+}$-dependent facilitation of Cav2.1 occurs at very short interstimulus intervals (ISIs) (5-50 msec) (Cuttle et al., 1998), whereas recovery from channel inactivation occurs within seconds (Forsythe et al., 1998). In contrast, the voltage-dependent relief of G-protein-mediated inhibition of Cav2.2 channels decays with a time constant of 75-100 msec (Zhang et al., 1996; Currie and Fox, 1997; Zamponi and Snutch, 1998a). We compared the effects of $\omega$-conotoxin and $\omega$-agatoxin on paired stimuli delivered at an ISI of either 50 or $500 \mathrm{msec}$, and PPRs were estimated as above (Fig. 3). After application of $\omega$-conotoxin GVIA and subsequent restoration of the quantal content of the first EPSC, $\mathrm{PPR}_{50}$ was reduced by $14.3 \pm 2.4 \%$, whereas $\mathrm{PPR}_{500}$ was not significantly affected $(-1.8 \pm 3.0 \%$; $n=$ $8 ; p=0.6)$. Similarly, application of $\omega$-agatoxin IVA caused an increase in $\mathrm{PPR}_{50}(+12.1 \pm 2.6 \%)$ but not in $\mathrm{PPR}_{500}(-2.4 \pm$ $3.4 \% ; n=6 ; p=0.8)$.

As observed by other groups (Debanne et al., 1996), facilitation for an ISI of $500 \mathrm{msec}$ was significantly less than at $50 \mathrm{msec}$ (PPR, $1.11 \pm 0.04$ vs $1.58 \pm 0.08 ; n=14 ; p<0.001)$. The difference in the effects of either toxin on release probability at different intervals suggests that these effects might depend on the initial amount of synaptic facilitation. However, we found no significant correlation between control PPR and the effect of either toxin on PPR ( $p>0.05$ for both 50 and $500 \mathrm{msec}$ ISI) (supplemental Fig. 1, available at www.jneurosci.org as supplemental material). We thus conclude that Cav2.1 and Cav2.2 have different effects on transmitter release during repetitive afferent stimulation at short $(50 \mathrm{msec})$ but not longer (500 msec) intervals.

Figure 4. Release dynamics during bursts of high-frequency afferent stimulation. $A$, Bursts of 10 afferent stimuli delivered at $20 \mathrm{~Hz}$ in a CA1 pyramidal cell held at $-60 \mathrm{mV}$. In this cell, repeated stimuli caused an initial facilitation, followed by depression. After application of $\omega$-conotoxin GVIA (Ctx; $2 \mu \mathrm{m}$ ) and subsequent recovery of the quantal content of the first EPSC, depression was observed for all EPSCs in the train. Each trace represents the average of 30 consecutive episodes. $B$, Plot of PPRs for all individual EPSCs in the train. Note that a decreased PPR is observed for virtually all EPSCS. C, Summary data from eight independent experiments showing the change in amplitude of both the second and the average of the last five EPSC s of the train, after application of the toxin compared with control. D, E, Similar experiment using $\omega$-agatoxin IVA (Atx). In this cell, PPD was observed for all EPSCs in the train in control conditions. After application of the toxin and recovery of the quantal content of the first EPSC, PPRs of almost all EPSCs were increased and exceeded 1. F, Summary plot of four independent experiments.

At the calyx of Held, in which presynaptic calcium currents can be recorded directly, calcium currents through Cav2.1 channels exhibit Ca-dependent facilitation followed by a rapid inactivation during sustained high-frequency stimulation (Forsythe et al., 1998). In contrast, currents carried by both Cav2.1 and Cav2.2 channels expressed in tsA201 cells are persistently facilitated in responses to trains of action potential waveforms (Currie and Fox, 2002), likely reflecting a voltage-dependent relief of G-protein-mediated inhibition. We thus compared release dynamics during trains of afferent stimuli after blockade of either channel subtype and restoration of quantal content (Fig. 4). Trains of 10 afferent stimuli at $20 \mathrm{~Hz}$ were delivered to CA1 cells, and the mean amplitude ratio of each EPSC to the first $\left(\mathrm{EPSC}_{\mathrm{i}} /\right.$ EPSC $_{1}$ ) was computed. Typically, the second EPSC was facilitated $\left(\mathrm{EPSC}_{2} / \mathrm{EPSC}_{1}, 1.07 \pm 0.06\right.$ ), and following EPSCs were progressively depressed $\left(\mathrm{EPSC}_{10} / \mathrm{EPSC}_{1}, 0.86 \pm 013 ; n=12\right)$. Facilitation at $50 \mathrm{msec}$ ISI was less than in previous experiments using pairs of stimuli, perhaps reflecting an incomplete recovery of the readily releasable pool of vesicles at synapses repeatedly stimulated by $20 \mathrm{~Hz}$ trains at $0.1 \mathrm{~Hz}$ (Fuhrmann et al., 2004). After application of $2 \mu \mathrm{M} \omega$-conotoxin GVIA and recovery of the quantal content of the first EPSC (to $100.4 \pm 0.5 \%$ of control), virtually all EPSCs in the train were depressed compared with control (Fig. $4 B$ ). We distinguished an "early" effect on the second EPSC in the train $(-19.3 \pm 5.3 \%$ of control; $n=8 ; p<0.02)$ and a "late" effect computed from the last five EPSCs in the train $(-13.5 \pm 2.8 \%$ of control; $p<0.03)$. Conversely, application of $200 \mathrm{~nm} \omega$-agatoxin IVA and subsequent restoration of the first EPSC (to $99.8 \pm 0.4 \%$ of control) led to a facilitation of all EPSCs in the train (Fig. $4 D-F$ ): early and late facilitations reached $+18.9 \pm 5.6$ and $+15.4 \pm 7.0 \%$ of control, respectively $(n=4$; 
A

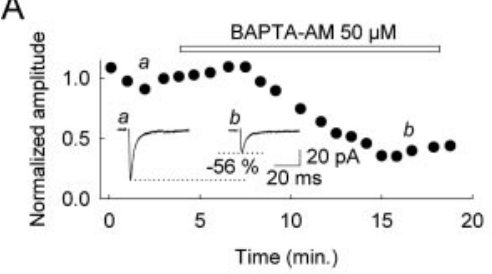

C

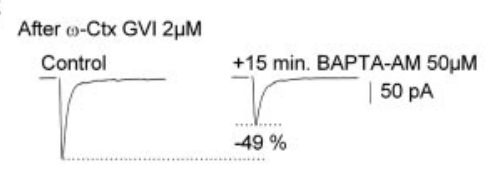

After $\omega$-Atx IVA 200nM

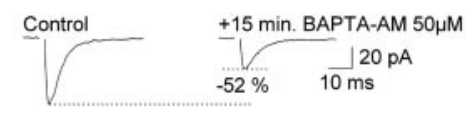

B

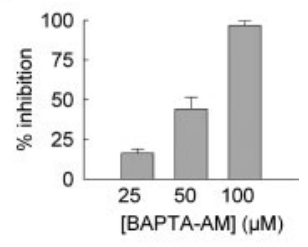

D

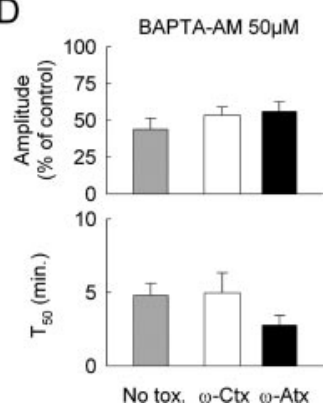

Figure 5. The fast, membrane-permeable $\mathrm{Ca}^{2+}$ buffer BAPTA-AM has similar effects on transmission mediated by Cav2.1 and Cav2.2. A, Application of BAPTA-AM (50 $\mu \mathrm{M})$ caused a $56 \%$ reduction in EPSC amplitude. Note that the effect of BAPTA-AM reached a steady state within 10-12 min of application. Each trace represents the average of 30 consecutive episodes. $B$, Dose-response relationship for the effect of BAPTA-AM on evoked EPSCs in seven independent experiments. The mean amplitude of 20 consecutive EPSCs was measured before and 15 min after application of BAPTA-AM. C, Effect of $50 \mu \mathrm{m}$ BAPTA-AM on evoked EPSC amplitude after application of $\omega$-conotoxin GVIA ( $2 \mu \mathrm{m}$; top) or $\omega$-agatoxin IVA ( $200 \mathrm{~nm}$; bottom). Recordings were made in the presence of $4 \mathrm{~mm} \mathrm{Ca}{ }^{2+}$ and $1 \mathrm{~mm} \mathrm{Mg}^{2+}$ in the external solution. In both cases, the reduction in EPSC amplitude after 15 min of BAPTA-AM application was $\sim 50 \%$. D, Summary data from eight ( $\omega$-conotoxin GVIA) and seven ( $\omega$-agatoxin IVA) experiments. There was no significant difference in the effects of BAPTA-AM on $\omega$-conotoxin- and $\omega$-agatoxinresistant EPSCs ( $p=0.8$ ). These effects were also undistinguishable from those on control EPSCs recorded in the absence of toxin ( $p=0.4$ and 0.7 , respectively).

$p<0.04)$. We conclude that the differential effect of Cav2.1 and Cav2.2 on release dynamics (1) is expressed at high $(20 \mathrm{~Hz})$ but not at low $(2 \mathrm{~Hz})$ stimulation frequency, (2) is independent of the initial level of facilitation, and (3) persists during sustained highfrequency stimulation. We next aimed at identifying the mechanisms responsible for this effect.

\section{Fast presynaptic calcium buffering similarly affects synapses} operating with either channel subtype

At immature neuromuscular junctions and calyx-type synapses of the trapezoid body in which both channels are expressed presynaptically, Cav2.2 are less efficient than Cav2.1 in triggering release (Wu et al., 1999; Rosato-Siri et al., 2002). This may reflect a greater distance from Cav2.2 channels to the calcium sensor, which could underlie a facilitating effect of these channels on release during repeated stimulation: $\mathrm{Ca}^{2+}$ entering from more distant channels is more likely to be damped by endogenous buffers, and saturation of such buffers has been shown to underlie PPF at several synapses (Blatow et al., 2003). $\mathrm{Ca}^{2+}$ influx during the first stimulation would locally saturate the buffers, permitting subsequent calcium entry to trigger release more effectively.

We tested whether Cav2.1 and Cav2.2 channels may be differentially coupled to the release machinery at SC synapses onto CA1 cells by comparing the sensitivity to the fast, membranepermeable $\mathrm{Ca}^{2+}$ chelator BAPTA-AM of transmitter release mediated by either channel subtype (Fig. 5). For these experiments, the concentration of BAPTA-AM was chosen to partially but not completely suppress transmission. We determined the doseresponse relationship of the effect of BAPTA-AM on synaptic

transmission at these synapses. BAPTA-AM at 25, 50, or $100 \mu \mathrm{M}$ was applied while monitoring the amplitude of EPSCs evoked by SC stimulation. Although $100 \mu \mathrm{M}$ BAPTA-AM almost completely blocked transmission within 10-15 min of application (by $96.8 \pm 2.8 \%$ of control), application of $50 \mu \mathrm{M}$ caused only a partial reduction of $44.0 \pm 7.6 \%$. This reduction was reached within $\sim 10$ min of BAPTA-AM application and remained stable over the next 5-10 min (Fig. 5A). We used this intermediate concentration of BAPTA-AM to compare the sensitivity to calcium buffering of transmitter release mediated by either channel subtype. After a $>6$ min application of the irreversible Cav2.2 antagonist $\omega$-conotoxin GVIA $(2 \mu \mathrm{M}), 50 \mu \mathrm{M}$ BAPTA-AM was thus applied for $15 \mathrm{~min}$ while monitoring EPSC amplitude (Fig. $5 C$ ). In these experiments, BAPTA-AM reduced EPSC amplitude by $53.6 \pm 5.6 \%(n=8)$. When applied after the irreversible Cav2.1 antagonist $\omega$-agatoxin GVIA (200 nM), BAPTA-AM caused a $56.1 \pm 6.7 \%$ reduction in EPSC amplitude. The effects of BAPTA-AM after either toxin were not significantly different from one another $(p=0.78)$ or from those on control EPSCs ( $p=0.38$ and 0.67 , respectively). Similarly, BAPTA-AM did not affect the $\mathrm{PPR}_{50}$ of evoked EPSCs differently after application of either toxin compared with control ( $p=0.86$ and 0.30 , respectively). Finally, the time of half-effect of BAPTA-AM $\left(T_{50}=\right.$ $4.8 \pm 0.8 \mathrm{~min}$ in control conditions) was unchanged after application of either toxin ( $p=0.82$ and 0.10 , respectively). Together, these results suggest that Cav2.2 and Cav2.1 have a similar spatial disposition with respect to the release machinery at SC synapses onto CA1 pyramidal cells.

\section{Blocking $\mathrm{G}_{\mathrm{o} / \mathrm{i}}$-proteins prevents channel subtype-dependent facilitation}

Cav2.1 and Cav2.2 channels both undergo voltage-dependent inhibition by G-proteins through direct interaction between $\mathrm{G}_{\beta \gamma}$ and $\alpha$ subunits of the channel (Dolphin, 1998; Zamponi and Snutch, 1998b). This inhibition is relieved by repetitive depolarizations, resulting in a progressive increase in the number of available channels (Park and Dunlap, 1998; Currie and Fox, 2002). If Cav2.2 channels were subject to stronger voltagedependent inhibition than Cav2.1 channels (Currie and Fox, 1997), transmission mediated by these channels should be more facilitated during repetitive stimulation.

We tested this hypothesis by comparing the effects of $\omega$-conotoxin and $\omega$-agatoxin in the presence and in the absence of pertussis toxin, which inhibits $G_{o}$ and $G_{i}$, the major neuronal G-proteins (Dolphin, 1998). Because the actions of pertussis toxin require long exposure times, organotypic slice cultures were used in these experiments. They were exposed to $500 \mathrm{ng} / \mathrm{ml}$ pertussis toxin for $48 \mathrm{hr}$ before recording (Tanabe et al., 1998) (see Materials and Methods). We confirmed that pertussis toxin inhibits $\mathrm{G}_{\mathrm{o} / \mathrm{i}}$ by testing the depression of evoked IPSCs by baclofen (Fig. 6A). This presynaptic action is mediated by $\mathrm{G}_{\mathrm{o} / \mathrm{i}}$ and is entirely suppressed by pertussis toxin (Potier and Dutar, 1993). In untreated slices, $10 \mu \mathrm{M}(-)$ baclofen depressed IPSC amplitude by $71.2 \pm 9.0 \%$ of control $(n=7 ; p<0.001)$. This effect was virtually abolished in slices exposed to pertussis toxin for $48 \mathrm{hr}$ $(-0.9 \pm 2.5 \%$ of control; $n=7 ; p=0.2)$.

In untreated slices, $\omega$-conotoxin GVIA and $\omega$-agatoxin IV1 depressed EPSC amplitude as in acute slices $(-65.6 \pm 3.7$ and $-68.4 \pm 8.1 \%$ of control; $n=7$ and 5 respectively). After application of $\omega$-conotoxin GVIA and subsequent restoration of the quantal content of the first EPSC, the PPR of EPSCs evoked at a $50 \mathrm{msec}$ interval was reduced to a similar extent as that observed in acute slices $(-16.9 \pm 4.9 \%$ of control; $n=5)$. Conversely, 
A
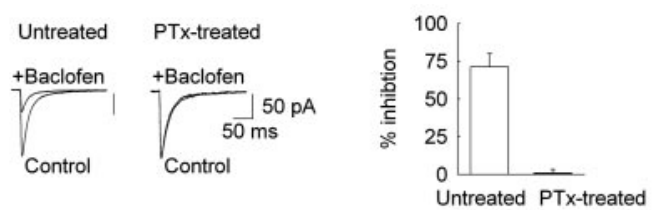

B

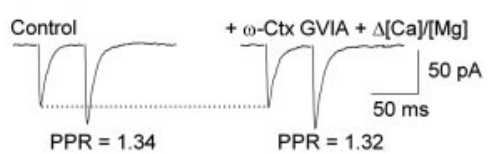

D

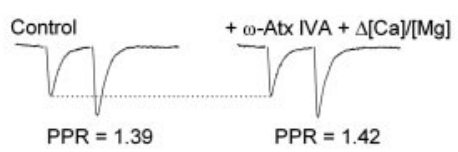

$\operatorname{PPR}=1.39$

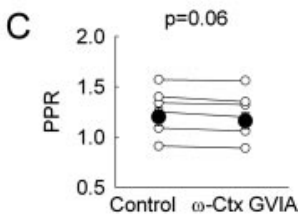

E

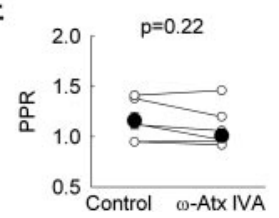

Figure 6. Pretreatment with the $\mathrm{G}_{\mathrm{i} / 0}$-protein antagonist pertussis toxin prevents the facilitating effect of Cav2.2 channels on transmission dynamics. A, Control of the efficacy of a $48 \mathrm{hr}$ pretreatment of hippocampal slices with PTx (2 times with $500 \mathrm{ng} / \mathrm{ml}$; see Materials and Methods). IPSCs evoked in CA1 pyramidal cells in the presence of NBQX and APV. In untreated slices, $10 \mu \mathrm{m}$ baclofen induced a $\sim 70 \%$ reduction in IPSC amplitude. In PTx-treated slices, however, the effect of baclofen was virtually abolished $(<1 \%)$. Bar chart represents summary data from seven independent experiments for each group ( $p<0.001$ ). B, C, Application of the Cav2.2 antagonist $\omega$-conotoxin GVIA (Ctx; $2 \mu \mathrm{m})$ and subsequent recovery of the quantal content of the first EPSC did not cause significant changes in $P P R_{50}$ in slices pretreated with pertussis toxin. Summary data from six independent experiments. $D, E$, Similar experiment using the Cav2.1 antagonist $\omega$-agatoxin IVA (Atx; $200 \mathrm{~nm}$ ). Again, the effect of the toxin on $\mathrm{PPR}_{50}$ was abolished by pretreatment with pertussis toxin. Summary data from six independent experiments. Each trace represents the average of 50 consecutive episodes.

application of $\omega$-agatoxin IVA led to an increase in $\mathrm{PPR}_{50}$ by $16.9 \pm 4.2 \%$ of control $(n=4)$. However, the effect of $\omega$-conotoxin GVIA was suppressed in slices treated with pertussis toxin $(-1.9 \pm 0.8 \%$ of control; $n=6 ; p=0.06$ ) (Fig. $6 B, C)$, as was the effect of $\omega$-agatoxin IVA $(-5.2 \pm 2.9 \%$ of control; $n=6$; $p=0.22$ ) (Fig. $6 D, E$ ). These results suggest that the greater facilitation of transmission mediated by Cav2.2 channels involves a greater tonic inhibition of these channels by $\mathrm{G}_{\mathrm{o} / \mathrm{i}}$. Such tonic inhibition could arise from activation of several presynaptic, G-protein-coupled receptors (Hille, 1994). In particular, GABA and glutamate both activate presynaptic metabotropic receptors that inhibit Cav2.2 channels (Wu and Saggau, 1995; Zhang and Schmidt, 1999). We thus examined the effects of antagonists of these receptors on release dynamics. Neither the $\mathrm{GABA}_{\mathrm{B}}$ receptor antagonist CGP52432 ([3-[[(3,4-dichlorophenyl)-methyl]amino] propyl](diethoxymethyl)phosphinic acid) $(10 \mu \mathrm{M})$ nor the broadspectrum metabotropic glutamate (mGlu) receptor antagonist MCPG [(RS)- $\alpha$-methyl-4-carboxyphenylglycine] $(250 \mu \mathrm{M})$ caused significant changes in $\mathrm{PPR}_{50}(-4.0 \pm 5.7 \%, p=0.6 ;+10.0 \pm$ $11.4 \%, p=0.8 ; n=6$ and 7 cells, respectively; data not shown).

\section{Discussion}

We show that selective blockade of either Cav2.1 or Cav2.2 at the same synapses onto CA1 neurons differentially affects release dynamics. Blockade of Cav2.1 leads to enhanced PPF, whereas blockade of Cav2.2 reduces it. This effect is present at short (50 $\mathrm{msec}$ ) but not longer (500 msec) interstimulus intervals and persists during sustained activity. It is not attributable to a differential coupling of either channel subtype to the release machinery but rather seems to reflect a stronger, tonic G-protein-mediated inhibition of Cav2.2. Thus, differential modulation of distinct

presynaptic calcium channels by G-protein-mediated pathways may provide the basis for a switch between different modes of dynamic filtering of synaptic transmission.

Traditionally, short-term synaptic facilitation is attributed to accumulation of intraterminal $\mathrm{Ca}^{2+}$, whereas depression reflects depletion of readily-releasable vesicles of transmitter. However, other mechanisms are simultaneously engaged during repetitive activity and contribute to the dynamic behavior of transmitter release (Zucker and Regehr, 2002). We wanted to examine how distinct presynaptic calcium channels contribute to short-term synaptic plasticity. Our experiments were therefore designed to control for contributions of these other mechanisms. First, we compared transmission at the same synapses operating with both Cav2.1 and Cav2.2 and then with either subtype, thus eliminating the influence of variability between synapses. Second, PPRs were measured in conditions of constant release probability. Several reports have shown that short-term plasticity strictly depends on release probability (Debanne et al., 1996; Dobrunz and Stevens, 1997). Accordingly, as EPSCs were reduced in amplitude by both $\omega$-toxins, PPR always increased ( +22 and $+40 \%$, respectively). The differential effect of the toxins on PPR was apparent only when the quantal content of $\mathrm{EPSC}_{1}$ was restored. Our comparison of changes in release dynamics at a constant release probability may explain differences with previous results obtained at autapses in cultured hippocampal neurons (Brody and Yue, 2000). This paradigm also prevented biases attributable to transmitter release itself, such as activation of presynaptic receptors (Baskys and Malenka, 1991; Debanne et al., 1996) and postsynaptic receptor desensitization (Jones and Westbrook, 1996).

We could not directly compare transmission mediated exclusively by Cav2.1 or Cav2.2. Instead, release dynamics were compared when presynaptic $\mathrm{Ca}^{2+}$ influx was carried by both subtypes and after blockade of one of them. Changes in PPR observed after application of $\omega$-conotoxin and $\omega$-agatoxin $(-15.3$ and $+15.9 \%$, respectively) may then underestimate the differences in PPR that would result from switching from one channel subtype to the other. This difference might be difficult to compute without a precise knowledge of the relative contribution of Cav2.1, Cav2.2, and possibly other channel subtypes that may partially contribute to presynaptic $\mathrm{Ca}^{2+}$ influx at SC synapses. Because Cav2.3 channels do not participate in transmitter release at these synapses (Gasparini et al., 2001), the identity of such minority channels and their contribution to release $(<9 \%)$ (Poncer et al., 1997) thus remains to be examined.

Blocking Cav2.1 leads to enhanced PPF, whereas blocking Cav2.2 reduces PPF. This could reflect (1) a different cooperativity of the two subtypes with respect to the release process, (2) a greater facilitation of $\mathrm{Ca}^{2+}$ influx through Cav2.2, or (3) a greater depression of $\mathrm{Ca}^{2+}$ influx through Cav2.1.

At several central synapses in which Cav2.1 and Cav2.2 coexist, transmitter release is more steeply dependent on $\mathrm{Ca}^{2+}$ concentration when $\mathrm{Ca}^{2+}$ influx is carried by Cav2.1 rather than Cav2.2 (Mintz et al., 1995; Wu et al., 1999; Qian and Noebels, 2001). This difference might reflect a distinct disposition of the channels with respect to the release machinery (Wu et al., 1999). $\mathrm{Ca}^{2+}$ flowing through more remote channels is more likely damped by fast-acting buffers. Saturation of endogenous buffers (Blatow et al., 2003) may then affect release dynamics. However, our data show that the fast, membrane-permeable buffer BAPTA-AM depressed transmission mediated by Cav2.1 or Cav2.2 to a similar extent. We conclude that, at SC synapses onto CA1 cells, the arrangement of the two channel subtypes is not significantly different (Wu and Saggau, 1994b; Reid et al., 1998). 
The differential effect of Cav2.1 and Cav2.2 antagonists on release dynamics was blocked by pertussis toxin, suggesting the involvement of $\mathrm{G}_{\mathrm{o} / \mathrm{i}}$-proteins. How may G-protein activation mediate distinct actions of Cav2.1 and Cav2.2 on release dynamics? G-protein-coupled receptors are known to modulate both channel subtypes (Dolphin, 1998; Zamponi and Snutch, 1998b). Direct interaction between $\mathrm{G}_{\beta \gamma}$ complex and the $\alpha 1$ channel subunit shifts gating from a willing to a reluctant mode (Bean, 1989) in which the channel may either not open (Cav2.1) or open with altered kinetics (Cav2.2) (Colecraft et al., 2000). This inhibition is partially relieved by a depolarizing pulse (Bean, 1989) or trains of action potentials (Park and Dunlap, 1998; Currie and Fox, 2002). During repetitive presynaptic activity, channels that were inhibited may thus be gradually recruited, thereby increasing presynaptic calcium influx. This mechanism may account for the shortterm facilitation induced by $\mathrm{GABA}_{\mathrm{B}}$ or adenosine $\mathrm{A}_{1}$ receptor activation at excitatory autapses in cultured hippocampal neurons (Brody and Yue, 2000). Several reports in heterologous systems suggest that Cav2.2 is more strongly inhibited by G-proteins than Cav2.1 and that depolarization more effectively relieves inhibition (Bourinet et al., 1996; Currie and Fox, 1997; Colecraft et al., 2000). In addition, the shape of the depolarization differentially affects both channel subtypes (Currie and Fox, 2002). We suggest that presynaptic Cav2.2 at SC synapses onto CA1 neurons undergo stronger tonic, G-protein-mediated inhibition than do Cav2.1. During pairs or trains of presynaptic action potentials, relief from this inhibition causes more facilitation of $\mathrm{Ca}^{2+}$ influx through Cav2.2. Consistent with this conclusion, we observed that facilitation of release mediated by Cav2.2 channels occurs at intervals of 50 but not $500 \mathrm{msec}$. Such kinetics are compatible with those of the voltage-dependent relief of Cav2.2 inhibition by G-proteins ( $\tau \sim 30-100 \mathrm{msec}$ ) (Currie and Fox, 1997; Park and Dunlap, 1998). Several presynaptic, G-protein-coupled receptors might be responsible for a more pronounced tonic inhibition of Cav2.2 at SC synapses onto CA1 cells (Wu and Saggau, 1995). We showed that antagonists of $\mathrm{GABA}_{\mathrm{B}}$ and $\mathrm{mGlu}$ receptors had no effect on PPR, suggesting that these receptors are not involved in the tonic inhibition of Cav2.2. Other candidates include adenosine $A_{1}$ (Wu and Saggau, 1994a), endocannabinoid $\mathrm{CB}_{1}$ (Wilson et al., 2001; Alger, 2002), adrenergic $\alpha 2$ (Boehm, 1999), and NPY-2 receptors (Qian et al., 1997). Possibly the tonic inhibition of Cav2.2 depends on activation of one or more of these receptors or even on a constitutive, ligand-independent activity (Milligan, 2003).

Calcium channels undergo both $\mathrm{Ca}^{2+}$-dependent (Budde et al., 2002) and intrinsic, voltage-dependent inactivation (Stotz and Zamponi, 2001). A different degree of inactivation of Cav2.1 and Cav2.2 might contribute to the differences in PPF observed when transmission is mediated by either subtype. Although a more pronounced inactivation of Cav2.1 may have contributed to the reduced PPF observed after blockade of Cav2.2, the complete block of this effect by pertussis toxin suggests that this contribution was limited.

Our conclusions rely implicitly on the assumption that all stimulated terminals express both Cav2.1 and Cav2.2. Some recent reports, however, suggest that the two subtypes might not be uniformly distributed at hippocampal synapses (Reid et al., 2003). Cav2.2 channels could predominate at facilitating synapses, and Cav2.1 channels might be enriched at depressing synapses. Blocking either channel subtype would result in opposite changes in PPR but would reflect the sampling of distinct subsets of synapses rather than different properties of presynaptic $\mathrm{Ca}^{2+}$ channels. At least three observations argue against such a sce- nario. First, blocking either Cav2.1 or Cav2.2 without restoring quantal content to control always resulted in enhanced facilitation. Second, the heterogeneous distribution of $\mathrm{Ca}^{2+}$ channels observed at autapses in cultured hippocampal neurons was not correlated with release probability (Reid et al., 1997). Finally, the differential effect of Cav2.1 and Cav2.2 antagonists on release dynamics was suppressed by the $\mathrm{G}_{\mathrm{o} / \mathrm{i}}$ antagonist pertussis toxin. This effect thus more likely reflects a differential modulation of $\mathrm{Ca}^{2+}$ channel subtypes rather than distinct release probabilities at terminals expressing these channels.

Our results predict that synapses operating with Cav2.2 will show more facilitation than synapses operating with Cav2.1, thereby operating a differential temporal filtering of synaptic transmission. Consistent with this prediction, hippocampal GABAergic synapses expressing Cav2.2 alone show more PPF at short interstimulus intervals than synapses expressing Cav2.1 only (Poncer et al., 2000). Perhaps more convincing is the increased PPF observed at SC synapses onto CA1 cells in the tottering mutant mouse. In these mice, a mutation in the pore-forming region of Cav2.1 (Fletcher et al., 1996) drastically reduces the contribution of Cav2.1 channels to presynaptic $\mathrm{Ca}^{2+}$ influx in favor of Cav2.2 (Qian and Noebels, 2000). In the same mice, transmitter release showed stronger inhibition by G-proteincoupled receptors, consistent with a more prominent inhibition of Cav2.2 compared with Cav2.1 (Zhou et al., 2003).

In conclusion, our results show that G-protein-mediated inhibition of presynaptic Cav2.1 or Cav2.2 impact release dynamics more than would be expected from the decrease in $\mathrm{Ca}^{2+}$ influx resulting from this inhibition. Although the stronger G-proteinmediated inhibition of Cav2.2 may depress transmitter release in response to phasic presynaptic activity, the voltage-dependent relief from this inhibition underlies a persistent facilitation of synaptic transmission during high-frequency activity.

\section{References}

Agler HL, Evans J, Colecraft HM, Yue DT (2003) Custom distinction in the interaction of G-protein beta subunits with N-type (CaV2.2) versus P/Qtype (CaV2.1) calcium channels. J Gen Physiol 121:495-510.

Alger BE (2002) Retrograde signaling in the regulation of synaptic transmission: focus on endocannabinoids. Prog Neurobiol 68:247-286.

Baskys A, Malenka RC (1991) Agonists at metabotropic glutamate receptors presynaptically inhibit EPSCs in neonatal rat hippocampus. J Physiol (Lond) 444:687-701.

Bean BP (1989) Neurotransmitter inhibition of neuronal calcium currents by changes in channel voltage dependence. Nature 340:153-156.

Blatow M, Caputi A, Burnashev N, Monyer H, Rozov A (2003) $\mathrm{Ca}^{2+}$ buffer saturation underlies paired pulse facilitation in calbindin-D28kcontaining terminals. Neuron 38:79-88.

Boehm S (1999) Presynaptic alpha2-adrenoceptors control excitatory, but not inhibitory, transmission at rat hippocampal synapses. J Physiol (Lond) 519:439-449.

Bourinet E, Soong TW, Stea A, Snutch TP (1996) Determinants of the G protein-dependent opioid modulation of neuronal calcium channels. Proc Natl Acad Sci USA 93:1486-1491.

Brager DH, Luther PW, Erdelyi F, Szabo G, Alger BE (2003) Regulation of exocytosis from single visualized GABAergic boutons in hippocampal slices. J Neurosci 23:10475-10486.

Brody DL, Yue DT (2000) Relief of G-protein inhibition of calcium channels and short-term synaptic facilitation in cultured hippocampal neurons. J Neurosci 20:889-898.

Budde T, Meuth S, Pape HC (2002) Calcium-dependent inactivation of neuronal calcium channels. Nat Rev Neurosci 3:873-883.

Catterall WA (1995) Structure and function of voltage-gated ion channels. Annu Rev Biochem 64:493-531.

Colecraft HM, Patil PG, Yue DT (2000) Differential occurrence of reluctant openings in G-protein-inhibited $\mathrm{N}$ - and P/Q-type calcium channels. J Gen Physiol 115:175-192. 
Currie KP, Fox AP (1997) Comparison of N- and P/Q-type voltage-gated calcium channel current inhibition. J Neurosci 17:4570-4579.

Currie KP, Fox AP (2002) Differential facilitation of N- and P/Q-type calcium channels during trains of action potential-like waveforms. J Physiol (Lond) 539:419-431.

Cuttle MF, Tsujimoto T, Forsythe ID, Takahashi T (1998) Facilitation of the presynaptic calcium current at an auditory synapse in rat brainstem. J Physiol (Lond) 512:723-729.

Debanne D, Guerineau NC, Gahwiler BH, Thompson SM (1996) Pairedpulse facilitation and depression at unitary synapses in rat hippocampus: quantal fluctuation affects subsequent release. J Physiol (Lond) 491:163-176.

Dietrich D, Kirschstein T, Kukley M, Pereverzev A, von der Brelie C, Schneider T, Beck H (2003) Functional specialization of presynaptic $\mathrm{Ca}_{\mathrm{v}} 2.3$ $\mathrm{Ca}^{2+}$ channels. Neuron 39:483-496.

Dobrunz LE, Stevens CF (1997) Heterogeneity of release probability, facilitation, and depletion at central synapses. Neuron 18:995-1008.

Dolphin AC (1998) Mechanisms of modulation of voltage-dependent calcium channels by $\mathrm{G}$ proteins. J Physiol (Lond) 506:3-11.

Fletcher CF, Lutz CM, O'Sullivan TN, Shaugnessy JD, Hawkes R, Frankel WN, Copeland NG, Jenkins NA (1996) Absence epilepsy in tottering mutant mice is associated with calcium channel defects. Cell 87:607-617.

Forsythe ID, Tsujimoto T, Barnes-Davies M, Cuttle MF, Takahashi T (1998) Inactivation of presynaptic calcium current contributes to synaptic depression at a fast central synapse. Neuron 20:797-807.

Fuhrmann G, Cowan A, Segev I, Tsodyks M, Stricker C (2004) Multiple mechanisms govern the dynamics of depression at neocortical synapses of young rats. J Physiol (Lond) 557:415-438.

Gasparini S, Kasyanov AM, Pietrobon D, Voronin LL, Cherubini E (2001) Presynaptic R-type calcium channels contribute to fast excitatory synaptic transmission in the rat hippocampus. J Neurosci 21:8715-8721.

Hille B (1968) Charges and potentials at the nerve surface. Divalent ions and pH. J Gen Physiol 51:221-236.

Hille B (1994) Modulation of ion-channel function by G-protein-coupled receptors. Trends Neurosci 17:531-536.

Jensen K, Mody I (2001) L-Type $\mathrm{Ca}^{2+}$ channel-mediated short-term plasticity of GABAergic synapses. Nat Neurosci 4:975-976.

Jones MV, Westbrook GL (1996) The impact of receptor desensitization on fast synaptic transmission. Trends Neurosci 19:96-101.

Kim J, Alger BE (2001) Random response fluctuations lead to spurious paired-pulse facilitation. J Neurosci 21:9608-9618.

Liang H, DeMaria CD, Erickson MG, Mori MX, Alseikhan BA, Yue DT (2003) Unified mechanisms of $\mathrm{Ca}^{2+}$ regulation across the $\mathrm{Ca}^{2+}$ channel family. Neuron 39:951-960.

Luebke JI, Dunlap K, Turner TJ (1993) Multiple calcium channel types control glutamatergic synaptic transmission in the hippocampus. Neuron 11:895-902.

Milligan G (2003) Constitutive activity and inverse agonists of G proteincoupled receptors: a current perspective. Mol Pharmacol 64:1271-1276.

Mintz IM, Sabatini BL, Regehr WG (1995) Calcium control of transmitter release at a cerebellar synapse. Neuron 15:675-688.

Musleh W, Bi X, Tocco G, Yaghoubi S, Baudry M (1997) Glycine-induced long-term potentiation is associated with structural and functional modifications of alpha-amino-3-hydroxyl-5-methyl-4-isoxazolepropionic acid receptors. Proc Natl Acad Sci USA 94:9451-9456.

Park D, Dunlap K (1998) Dynamic regulation of calcium influx by G-proteins, action potential waveform, and neuronal firing frequency. J Neurosci 18:6757-6766.

Poncer JC, McKinney RA, Gahwiler BH, Thompson SM (1997) Either N- or P-type calcium channels mediate GABA release at distinct hippocampal inhibitory synapses. Neuron 18:463-472.

Poncer JC, McKinney RA, Gahwiler BH, Thompson SM (2000) Differential control of GABA release at synapses from distinct interneurons in rat hippocampus. J Physiol (Lond) 528:123-130.

Potier B, Dutar P (1993) Presynaptic inhibitory effect of baclofen on hippocampal inhibitory synaptic transmission involves a pertussis toxinsensitive G-protein. Eur J Pharmacol 231:427-433.
Qian J, Noebels JL (2000) Presynaptic $\mathrm{Ca}^{2+}$ influx at a mouse central synapse with $\mathrm{Ca}^{2+}$ channel subunit mutations. J Neurosci 20:163-170.

Qian J, Noebels JL (2001) Presynaptic $\mathrm{Ca}^{2+}$ channels and neurotransmitter release at the terminal of a mouse cortical neuron. J Neurosci 21:3721-3728.

Qian J, Colmers WF, Saggau P (1997) Inhibition of synaptic transmission by neuropeptide $\mathrm{Y}$ in rat hippocampal area $\mathrm{CA1}$ : modulation of presynaptic $\mathrm{Ca}^{2+}$ entry. J Neurosci 17:8169-8177.

Regehr WG, Mintz IM (1994) Participation of multiple calcium channel types in transmission at single climbing fiber to Purkinje cell synapses. Neuron 12:605-613.

Reid CA, Clements JD, Bekkers JM (1997) Nonuniform distribution of $\mathrm{Ca}^{2+}$ channel subtypes on presynaptic terminals of excitatory synapses in hippocampal cultures. J Neurosci 17:2738-2745.

Reid CA, Bekkers JM, Clements JD (1998) N- and P/Q-type $\mathrm{Ca}^{2+}$ channels mediate transmitter release with a similar cooperativity at rat hippocampal autapses. J Neurosci 18:2849-2855.

Reid CA, Bekkers JM, Clements JD (2003) Presynaptic $\mathrm{Ca}^{2+}$ channels: a functional patchwork. Trends Neurosci 26:683-687.

Rosato-Siri MD, Uchitel OD (1999) Calcium channels coupled to neurotransmitter release at neonatal rat neuromuscular junction. J Physiol (Lond) 514:533-540.

Rosato-Siri MD, Piriz J, Tropper BA, Uchitel OD (2002) Differential $\mathrm{Ca}^{2+}$. dependence of transmitter release mediated by P/Q- and N-type calcium channels at neonatal rat neuromuscular junctions. Eur J Neurosci 15:1874-1880.

Stotz SC, Zamponi GW (2001) Structural determinants of fast inactivation of high voltage-activated $\mathrm{Ca}^{2+}$ channels. Trends Neurosci 24:176-181.

Takahashi T, Momiyama A (1993) Different types of calcium channels mediate central synaptic transmission. Nature 366:156-158.

Tanabe M, Gahwiler BH, Gerber U (1998) Effects of transient oxygenglucose deprivation on G-proteins and G-protein-coupled receptors in rat CA3 pyramidal cells in vitro. Eur J Neuorsci 10:2037-2045.

Wheeler DB, Randall A, Tsien RW (1994) Roles of N-type and Q-type Ca ${ }^{2+}$ channels in supporting hippocampal synaptic transmission. Science 264:107-111.

Wilson RI, Kunos G, Nicoll RA (2001) Presynaptic specificity of endocannabinoid signaling in the hippocampus. Neuron 16:453-462.

Wu LG, Saggau P (1994a) Adenosine inhibits evoked synaptic transmission primarily by reducing presynaptic calcium influx in area CA1 of hippocampus. Neuron 12:1139-1148.

Wu LG, Saggau P (1994b) Pharmacological identification of two types of presynaptic voltage-dependent calcium channels at CA3-CA1 synapses of the hippocampus. J Neurosci 14:5613-5622.

Wu LG, Saggau P (1995) GABAB receptor-mediated presynaptic inhibition in guinea-pig hippocampus is caused by reduction of presynaptic $\mathrm{Ca}^{2+}$ influx. J Physiol (Lond) 485:649-657.

Wu LG, Westenbroek RE, Borst JG, Catterall WA, Sakmann B (1999) Calcium channel types with distinct presynaptic localization couple differentially to transmitter release in single calyx-type synapses. J Neurosci 19:726-736.

Zamponi GW, Snutch TP (1998a) Decay of prepulse facilitation of N type calcium channels during $\mathrm{G}$ protein inhibition is consistent with binding of a single Gbeta subunit. Proc Natl Acad Sci USA 95:4035-4039.

Zamponi GW, Snutch TP (1998b) Modulation of voltage-dependent calcium channels by $\mathrm{G}$ proteins. Curr Opin Neurobiol 8:351-356.

Zhang C, Schmidt JT (1999) Adenosine Al and class II metabotropic glutamate receptors mediate shared presynaptic inhibition of retinotectal transmission. J Neurophysiol 82:2947-2955.

Zhang JF, Ellinor PT, Aldrich RW, Tsien RW (1996) Multiple structural elements in voltage-dependent $\mathrm{Ca}^{2+}$ channels support their inhibition by G proteins. Neuron 17:991-1003.

Zhou YD, Turner TJ, Dunlap K (2003) Enhanced G protein-dependent modulation of excitatory synaptic transmission in the cerebellum of the $\mathrm{Ca}^{2+}$ channel-mutant mouse, tottering. J Physiol (Lond) 547:497-507.

Zucker RS, Regehr WG (2002) Short-term synaptic plasticity. Annu Rev Physiol 64:355-405. 